\title{
Informação, tecnologia e mediações culturais
}

\author{
Marco Antônio de Almeida
}

\begin{abstract}
Doutor em Ciências Sociais, docente do curso de Ciências da Informação e Documentação da FFCLRP-USP e do Programa de Pós-Graduação em Ciência da Informação da ECA-USP.
\end{abstract}

As tecnologias de informação e comunicação, ao apontarem novas formas de produção, circulação e recepção de produtos simbólicos, contribuíram, juntamente com a discussão estética relacionada à pósmodernidade, para tornar a atual cena cultural cada vez mais complexa. Múltiplas camadas de informação se agregam aos produtos culturais, sinalizando a constituição de um novo tipo de "conhecimento" necessário para a crítica e compreensão das obras. O artigo reflete sobre esse processo, concentrando-se na informação cultural presente na Internet.

Palavras-chave: Cultura; Mediação; Crítica; Informação; Tecnologias de Informação e Comunicação.

\section{Information, technology and cultural mediations}

The information and communication technologies, to suggest new ways of production, circulation and reception of symbolic products, contributing together with the aesthetic discussion related to post-modernity, to make the current cultural scene becoming increasingly complex. Multiple layers of information are added to the cultural products, signaling the formation of a new type of "knowledge" necessary for the critical and understanding of the works. The article reflects on this process, focusing on cultural information present on the Internet.

Keywords: Culture; Mediation; Review, Information, Information and Communication Technologies. 


\section{Introdução ${ }^{1}$}

Conexões interdisciplinares são um desafio permanente - um exemplo disso está na dificuldade de conectar os domínios díspares da cultura, da economia e da informação, especialmente agora, no âmbito de uma "Sociedade da Informação" que concorreria para redimensionar estes conceitos. Este artigo não pretende, obviamente, dar conta de tão complexa relação - mais modestamente, buscar-se-á refletir acerca de como as tecnologias de informação e comunicação (TICs), ao descortinarem inéditas formas de produção, circulação e recepção de produtos simbólicos, também contribuíram para tornar a cena cultural contemporânea cada vez mais complexa. Múltiplas camadas de informação se agregam aos produtos culturais e em torno deles, sinalizando a constituição de um novo tipo de "conhecimento" necessário para a crítica, o consumo, e, no limite, para a própria compreensão dessas mercadorias singulares.

A lógica da economia clássica tendeu, historicamente, a se defrontar com os fenômenos culturais na sua qualidade de espetáculos e exibições ao vivo ou de patrimônios culturais. O surgimento das indústrias culturais irá implicar numa nova lógica mercantil e social. Não caberia aqui retomar a clássica discussão acerca da indústria cultural de Adorno e Horkheimer (1986), mas observar que o acesso à cultura, a partir do século XX, passou a se processar muito mais por meio dos produtos culturais do que propriamente pelo contato direto com a criação e apresentação artística. Hoje essa tendência é claramente perceptível entre os jovens com acesso cada vez mais precoce à tecnologia digital, e que incorporam crescentemente o consumo de produtos culturais "portáveis" ao seu cotidiano - o exemplo da música sendo talvez o caso mais extremo nesse sentido. Por outro lado, ainda que nesse caso a circulação da produção cultural se processe pelos produtos culturais, vale estender a eles pura e simplesmente a mesma lógica que se aplica às demais "mercadorias"?

No setor cultural ocorre o predomínio de uma lógica da oferta em oposição a uma lógica da demanda que seria mais característica de outros setores. Esta lógica da oferta relaciona-se, de um lado, à "convenção de originalidade" ${ }^{2}$ que domina o campo cultural, e, de outro lado, ao contexto de incerteza que predomina nesse setor, visto que tanto produtores como consumidores sabem que é impossível ter medidas universais e objetivas da qualidade dos produtos culturais. Como observa Paul Tolila:

\footnotetext{
1 Versão revista e ampliada de trabalho originalmente apresentado no I Colóquio "Mediações e Usos de Saberes e Informação: um diálogo França-Brasil" com o título "Mediação, informação, conhecimento: reflexões acerca da crítica cultural na contemporaneidade".

${ }^{2}$ Embora Adorno \& Horkheimer (1986) tenham chamado a atenção para todas as implicações da estandardização e homogeneização presentes na lógica da indústria cultural, Paul Tolila, entretanto, mostra que, desde o final do séc. XIX e início do séc. XX, as sociedades ocidentais passaram a avaliar a qualidade artística dos bens culturais a partir da convenção de "originalidade" (fundada no tripé autenticidade - unicidade - novidade). Embora pareça um paradoxo pensar em "originalidade" nos termos de uma produção industrial de objetos padronizados, "a produção cultural e artística busca voluntariamente promover e amplificar essa singularidade (o artista, o escritor, o diretor de cinema, o ator ...). O estilo e a assinatura são características essenciais." (TOLILA, 2007, p. 30)
} 
A convenção de qualidade artística, fundada na originalidade e na variedade, posiciona o bem cultural como protótipo único. Como cada protótipo é imprevisível, o controle da incerteza ligado à comercialização do produto é sempre imperfeito. Ele induz, contudo, a uma espécie de corrida pelo controle da informação por parte dos produtores. Para os mais poderosos deles, causa aumentos drásticos em termos de orçamentos de marketing e publicitários, o uso dos meios de comunicação de massa (rádios, televisões) como intermediários, ou ainda, a vontade de dominar os circuitos de difusão e exploração para diminuir os riscos. (TOLILA, 2007, 32)

Se a informação sobre os produtos (marketing) é estratégica para a circulação de qualquer tipo de mercadoria, no caso do setor cultural esse papel é ainda mais fundamental. Pode parecer, à primeira vista, que o ato de informar-se seria algo bastante simples - o que não é verdade. A multiplicação da quantidade de informações e o "ruído" decorrente antes dificultam do que facilitam esse processo. Além disso, seria necessário refletir acerca das estruturas de interpretação utilizadas para passar da recepção dessas informações à sua "organização" e incorporação como conhecimento. O termo "conhecimento" reconheça-se, é um pouco vago, especialmente quando seu uso prolifera em expressões tão abrangentes como "Sociedade do Conhecimento" ou "Gestão do Conhecimento". O que se quer salientar aqui, entretanto, é que a informação é secundária em relação aos sistemas de conhecimento - aos esquemas socioculturais de interpretação que dão à informação seu status e seu valor. São esses quadros de interpretação simbólica que permitem separar a informação relevante do "ruído" provocado pelo incessante e sempre crescente fluxo informacional. Cabe interrogar, portanto, de que maneira esses quadros simbólicos de interpretação são construídos e compartilhados. Nesse caso, o sistema da crítica cumpre papel fundamental.

Buscando mapear algumas tendências, comentaremos adiante exemplos de comunidades da internet relacionadas a informações sobre livros, música, filmes e quadrinhos, investigando como, a partir dos recursos possibilitados pelas novas tecnologias, o "consumidor cultural" contemporâneo pode exercer e acumular simultaneamente o papel de fã, crítico, consumidor e produtor cultural a partir da internet. Mas antes, torna-se necessário um breve apanhado sobre a formação e as transformações históricas da crítica, considerando-a como parte importante dos quadros sociais de interpretação simbólica das informações e conhecimentos sobre os produtos culturais.

\section{A crítica como instituição cultural e aparato informacional}

O que podemos chamar de crítica (seja ela literária, cinematográfica, teatral, pictórica ou, mais amplamente, cultural) corresponde, na realidade, a uma gama de atividades ligadas a redes e 
canais institucionais diferentes - do jornalismo à universidade, passando pelas revistas especializadas e, mais recentemente, pela televisão e pela Internet. Paralela à diversidade institucional coloca-se outra, relativa à heterogeneidade de operações discursivas, cujo laço comum não é fácil de identificar. Foram os usos e os hábitos que estabeleceram afinidades e parentescos entre as operações intelectuais reunidas sobre o nome genérico de crítica. Consideraremos a crítica como instituição cultural da Modernidade, para correlacioná-la a um sistema de produção e circulação de informações sobre bens culturais ${ }^{3}$. A necessidade social da literatura e a necessidade literária de um público leitor se imbricam mutuamente. Isso é fartamente demonstrado por Ian Watt (1990) em sua obra $A$ ascensão do romance: a partir de meados do séc. XVIII, ocorre uma maior produção de literatura e modificações em sua forma, com o surgimento e a consolidação do romance. Este aumento da oferta literária e do público leitor gera novas necessidades. Onde obter informações sobre os livros existentes? Quem pode proporcionar as chaves para interpretá-los e possibilitar construir os "quadros sociais do conhecimento" para sua compreensão? É aqui que começa a se esboçar a figura do crítico e da crítica como instituição sociocultural.

Historicamente, a atividade crítica, como a conhecemos e é praticada hoje, é um produto do século XIX. Isto porque antes do século XIX existiam críticos, mas não existia a crítica enquanto tal, considerada como atividade relacionada com uma camada profissional treinada para produzir opiniões autorizadas sobre livros, exposições e representações dramáticas/musicais. A crítica é, pois, uma categoria cultural moderna, apoiada não apenas sobre o princípio do caráter relativo dos valores literários, como também sobre o postulado romântico do valor da originalidade e sobre a idéia da necessidade de uma seleção e de uma eleição de obras, guiando, assim, o público frente a uma produção cada vez mais ampla e diversa. Sempre é bom lembrar que esses valores são, em geral, absolutizados pela própria construção de autoridade e legitimidade da crítica, segundo o mecanismo que rege a dinâmica da hierarquia dentro dos campos culturais na ótica de Pierre Bourdieu (1979; 1996). O crítico surge, portanto, como guia, como uma figura profissional da mediação, e sua primeira forma de articulação institucional foi o jornalismo (HABERMAS, 1984). Segundo Carlos Altamirano e Beatriz Sarlo (1993), para que a crítica adquira o caráter de disciplina será necessário outro ciclo, que é o da crítica universitária. Esta não substitui a primeira, mas ambas se sobrepõem, organizando redes institucionais diferentes e duas definições de crítica como atividade intelectual: de um lado como o exercício do gosto e da sensibilidade e de outro, como produto de um saber objetivo. A forma de ocupar espaços no interior do campo cultural também irá variar: desde a inserção nos meios massivos de circulação (jornais, principalmente) até a produção de veículos próprios, de

\footnotetext{
${ }^{3}$ Por instituição, do ponto de vista sociológico, compreendemos o conceito com o qual se identificam as formas padronizadas de comportamento e de relacionamento social, seguidas por um número expressivo de atores, em geral em coordenadas espaço-temporais relativamente amplas.
} 
circulação mais restrita, como as revistas, outro elemento importante para o campo da crítica. Por sua característica de instituição deliberadamente constituída para gerar opiniões dentro do campo intelectual, as revistas culturais optam como estratégia geral pela defesa e a propagação de certa "qualidade" (artística, mas que também não descarta valores da ética e da política).

Desde seu surgimento a crítica cultural sofreu transformações, mas não tão impactantes como as que ocorreram nos últimos anos, em função principalmente da ampliação da oferta de bens culturais e da pressão do mercado, e, numa escala menor, porém relacionada, do questionamento de determinados paradigmas estéticos identificados com a modernidade artística e que regiam a crítica cultural. Na análise da atual configuração histórica do campo da produção cultural torna-se necessário levar em conta, portanto, os debates em torno daquilo que uma série de autores, por falta de termo melhor, denominaram de pós-modernidade. Uma conseqüência importante para a linha de raciocínio desenvolvida por Bourdieu é o fato de que as fronteiras entre os subcampos tornaram-se cada vez mais fluídas, bem como a hierarquia entre os mesmos; as trocas se aceleram, não respeitando, inclusive, as fronteiras nacionais. Esse processo de diluição de fronteiras simbólicas, no contexto da globalização, não deve ser reduzido apenas à circulação de idéias e códigos culturais (como algumas análises superficiais podem sugerir), mas ser considerado, de maneira mais ampla, em relação às práticas sociais e econômicas, nas alterações promovidas nas disputas pelo poder local, propiciando alianças estratégicas ou disputas com os poderes externos. Néstor Garcia Canclini sintetiza os efeitos desse processo para a dinâmica contemporânea do campo da produção cultural:

De qualquer modo, a interação crescente entre o culto, o popular e o massivo abranda as fronteiras entre seus praticantes e seus estilos. Mas esta tendência luta contra o próprio movimento centrípeto de cada campo, em que os que detém $o$ poder fundamentado em retóricas e formas específicas de dramatização do prestígio supõem que sua força depende de preservar as diferenças. A dissolução das divisórias que os separam é vivida pelos que hegemonizam cada campo como ameaça a seu poder. Por isso, a reorganização atual da cultura não é um processo linear. (CANCLINI, 1997, p. 360)

Para Canclini, essa nova dinâmica do conflito dentro do campo cultural seria uma das causas da obsolescência freqüente dos bens culturais. As referências de legitimidade se sucedem velozmente, muitas vezes se sobrepondo, fazendo com que os produtores culturais tenham cada vez menos paradigmas consagrados para guiar suas ações. Dessa forma, o estado "pós-moderno" da cultura contemporânea parece ter redimensionado o papel da vanguarda - pelo menos nos termos como ela é pensada no esquema proposto por Bourdieu para a análise do campo literário. 
Para situarmos a análise da produção cultural no debate estético do Pós-Modernismo, vale lembrar o debate entre Fredric Jameson e Linda Hutcheon. Jameson propõe uma concepção histórica, e não meramente estilística, do pós-modernismo, considerando-o como a dominante cultural da lógica do capitalismo tardio. Correlaciona, dessa forma, a emergência de novas características formais na cultura com a emergência de novas formas sociais e econômicas. Uma das principais características do pósmodernismo seria a dissolução da esfera autônoma da cultura por sua expansão por todo o domínio do social, onde tudo passa a ser encarado como "cultural": do valor econômico e do poder do Estado às práticas e a própria estrutura da psique. Outra característica: a perda de percepção da profundidade histórica - habitamos agora a sincronia e não a diacronia, e a linguagem cultural contemporânea é dominada pelas categorias de espaço e não pelas de tempo, como no período anterior do Alto Modernismo. Dessa forma, o desaparecimento do sujeito individual e a inviabilidade de um estilo pessoal remetem ao pastiche. O pastiche tornase assim uma prática neutralizada de imitação e uma "canibalização" de estilos aleatória. O borramento das fronteiras da História reflete a incapacidade contemporânea de produzir representações acerca da própria experiência corrente. (JAMESON, 1996)

As estéticas pós-modernas constituíram-se, de um modo geral, seguindo esse movimento, utilizando e valorizando principalmente procedimentos de pilhagem cultural, como a intertextualidade, a citação, a paródia, a hibridização, a retomada, etc, sem, necessariamente, resultarem numa produção a-crítica. Hutcheon contesta a concepção de paródia adotada por Jameson (considerada apenas como imitação ridicularizadora), e que o levaria a concluir que no pós-modernismo ela teria sido substituída pelo pastiche, uma paródia neutra ou inexpressiva. Dessa forma, Hutcheon inverte o diagnóstico de Jameson, procurando mostrar que, onde ele vê a citação e a referência como signos de alienação histórica, o que existe, na realidade, é uma reflexão sobre a própria história, construída ironicamente. (HUTCHEON, 1991). Constituem-se, assim, duas visões distintas de um procedimento caro à estética pós-moderna, que é a presença constante da intertextualidade.

Independentemente de tomar partido de uma ou outra posição, o fato é que o debate sobre o pós-modernismo sinaliza um dado importante para a compreensão da cultura contemporânea: a intertextualidade, a citação, a paródia - enfim, o diálogo com as formas já estabelecidas pela produção artístico-cultural - configuram um horizonte de expectativas para essa mesma produção. Ou seja, é um discurso estético que influencia a produção, a recepção e a avaliação de filmes, livros, músicas, etc. O que explicaria, em parte, fenômenos como o neo-noir no cinema ou a revivência de gêneros como o noir e o gótico na literatura, a incorporação de ritmos tradicionais associados à música eletrônica, etc. Vale lembrar também as inovações tecnológicas que permitiram um maior acesso às produções culturais (no caso do cinema, por exemplo, a disponibilidade de filmes antigos em vídeo e sua contínua presença na televisão). Nesse caso, podemos perguntar em que medida as tecnologias de informação e 
comunicação (TICs) desempenham um papel importante nas configurações estéticas do pós-modernismo.

Jorge Luis Borges afirmava que as citações e referências eram procedimentos correntes na história da literatura ocidental: o segundo livro que se tinha notícia (a Odisséia) já era citação do primeiro (a Ilíada). Entretanto, durante toda a Antiguidade e a Idade Média, o acesso à informação sobre outras obras era difícil e reduzido a uma parcela mínima da população que constituía o público letrado. A invenção e disseminação da imprensa, a partir dos séculos XV/XVI, instauram um processo de ampliação crescente desse público e do volume de informações acerca das obras. A constituição de uma imprensa popular, no século XIX, e da indústria cultural, no século $X X$, consolidam o fenômeno de uma cultura e uma comunicação de massa (usamos o conceito na falta de outro melhor, apesar de todas as controvérsias em torno do mesmo que não poderemos explorar no âmbito deste texto). O acesso cada vez mais amplo às produções culturais e às informações acerca delas, proporcionado pelas TICs nesse novo contexto histórico, embaralhou os níveis de elaboração, circulação e fruição das obras, requerendo uma maior complexidade na análise desses fenômenos.

Uma importante contribuição para pensarmos, a partir dos traços de uma estética pós-moderna, a relação mediação cultural-crítica cultural, está na obra Lector in fabula (1986), de Umberto Eco. Ele afirma que, em geral, tanto os autores como os leitores, para atualizarem as estruturas discursivas, fazem uso de códigos e subcódigos fornecidos pelo sistema da língua em que o texto foi escrito e das tradições culturais relacionadas. Diferentemente de seus correspondentes empíricos, o Autor e o LeitorModelo de Eco são concebidos não como seres humanos de fato, mas como estratégias narrativas empregadas tanto na produção como na recepção de textos, que permitem que eles sejam atualizados em seus conteúdos potenciais: "prever o próprio Leitor-Modelo não significa somente 'esperar' que ele exista, mas significa também mover o texto de modo a construí-lo. O texto não apenas repousa numa competência, mas contribui para produzi-la" (ECO, 1986, p. 40). A "competência enciclopédica" refere-se a um dicionário de base (num nível propriamente semântico) enquanto a "competência intertextual" liga-se a uma enciclopédia hipercodificada registrada pela tradição retórica, conectada, portanto, a uma memória que comporta um certo número de informações.

O conceito de enciclopédia ou de conhecimento enciclopédico poderia ser traduzido, em outras palavras, como o patrimônio cultural (de um indivíduo ou de uma comunidade), que compreende toda a gama de experiências e informações, o conhecimento de convenções, o maior ou menor domínio dos códigos de linguagem, referenciais religiosos, sociais, políticos, etc. Desse modo, nenhum texto (e estamos compreendendo texto aqui no seu caráter mais aberto de produção cultural) pode ser lido independentemente da experiência de outros textos - e o grau dessa experiência determina diferenças substantivas entre os leitores: "As encenações intertextuais, pelo contrário, são esquemas retóricos e narrativos que fazem parte de um repertório selecionado e restrito de 
conhecimento que nem todos os membros de uma determinada cultura possuem" (ECO, 1986, p. 66). Assim, alguns leitores são vítimas de clichês, golpes teatrais, velhos esquemas de suspense ou terror que um leitor mais sofisticado, ao contrário, considera bastante banais, prevendo com mais facilidade o fim da história e, eventualmente, se deleitando com a violação de algumas regras narrativas que quebram as expectativas do leitor comum.

Em ensaios posteriores, Eco retoma alguns desses conceitos para refletir acerca dos paradoxos da fruição de obras culturais no contexto de uma situação pós-moderna. Trabalhando a partir de exemplos das diferentes utilizações da intertextualidade em produtos da cultura de massa, especialmente filmes e seriados, mostra que o espectador contemporâneo deve saber muitas coisas:

Deve, em suma, possuir não somente um conhecimento dos textos mas também um conhecimento do mundo, ou seja, das circunstâncias externas aos textos. Observe-se, naturalmente, que tanto o conhecimento dos textos como o conhecimento do mundo, não passam de dois capítulos do conhecimento enciclopédico e que, portanto, numa certa medida, o texto se refere sempre, seja como for, ao mesmo patrimônio cultural. Antigamente, um fenômeno desse gênero era típico de uma arte experimental que pressupunha um leitor modelo culturalmente assaz sofisticado. O fato de tais procedimentos serem sempre mais comuns no universo dos meios de comunicação de massa nos leva a algumas considerações: os mass media se preocupam com - pressupondo-as informações já veiculadas por outros mass media.(ECO, 1989, p. 127)

Eco reflete, desse modo, acerca da relação da obra artístico-cultural com o horizonte de expectativas e a enciclopédia do público. Assim, a obra deve ser examinada em conexão com a enciclopédia da época em que foi produzida, e também em conexão com a enciclopédia de seu público posterior: "e também nesse caso a comparação textual pode dizer-nos por que uma obra nascida com intenções de consumo pode, num período posterior, transformar-se em estímulo para experiências de leitura mais sofisticada." (ECO, 1989, p. 106). No caso de uma estética moderna, buscar-se-ia uma dialética entre novidade e repetição, entre esquematismo e inovação. Esse jogo com a variação é incentivado pelas obras mais sofisticadas, que incorporam os procedimentos de citação e auto-citação como características intrínsecas. Já no caso de uma estética pós-moderna, compreende-se que algumas obras contemporâneas (sejam da cultura erudita ou da cultura de massa) apontam para novas formas de arte que satisfazem à sensibilidade contemporânea.

Tudo isso leva Eco a indagar, provocadoramente, acerca do desaparecimento do leitor ingênuo: "De fato, não existe o leitor ingênuo de um quadro abstrato ou de uma escultura 'minimal' (ou se existe quem pergunte 'o que significa?' este não é leitor nem de primeiro nem de 
segundo nível, está fora de qualquer leitura)". Resta a questão: é possível esperar o mesmo dos leitores (dos "consumidores culturais") dos produtos culturais industrializados de massa do cinema, da televisão, das indústrias editorial e fonográfica? Devemos, portanto, como observa Eco, "pensar no nascimento de um novo público que, indiferente às histórias contadas, que já conhece, pretende apenas degustar a repetição e as suas mínimas variações?" (ECO, 1989, p. 136) Como situar a crítica cultural contemporânea em relação a esse estado de coisas? Nos termos de Eco, em que medida sua função não poderia ser pensada agora como um trabalho de mediação entre a enciclopédia dos públicos e a enciclopédia requerida pela fruição das obras? Como as novas tecnologias facilitam e/ou dificultam esse processo? Em que medida a crítica e o comentário cultural podem ser repensados nos termos de uma construção coletiva do conhecimento?

\section{Novas tecnologias e mediações: repensando o consumo e a crítica cultural}

Se tomarmos os exemplos do cinema e das histórias em quadrinhos, observaremos que, historicamente, a dinâmica de associação de aficcionados em torno dessas manifestações culturais é bem antiga, quase contemporânea ao surgimento de ambas. Associações de fãs e colecionadores se constituíram rapidamente, gerando espaços de discussão e troca (como clubes, cinematecas, gibitecas), produzindo e disseminando informação acerca do cinema e dos quadrinhos, por meio de produtos específicos (revistas, jornais, fanzines). Constituiu-se, assim, um circuito de circulação de informações e juízos de valor paralelo (muitas vezes em oposição) ao circuito da crítica (jornalística ou universitária).

Um aspecto importante a ser analisado na abordagem desses espaços é seu papel mediador entre o consumo cultural público e o privado. Nunca se assistiu a tantos filmes como hoje em dia; entretanto, essa fruição é principalmente doméstica, através da televisão e do vídeo. Trata-se da manifestação, nesse campo, de uma tendência mundial de decréscimo das participações em instalações públicas (cinemas, teatros, salões de concerto, auditórios) em contrapartida a uma oferta de cultura à domicílio (rádio, televisão, vídeo). Isso provoca uma grande modificação na concepção das atividades culturais, como, por exemplo, no que se entendia classicamente por "cinema": "O cinema ampliou sua ação comunicacional graças à televisão e ao vídeo. Mas esta expansão transformou o processo produtivo e a maneira de se assistir aos filmes." (CANCLINI, 1995, p. 178). O que a leitura de Canclini sugere é que temos hoje um campo cultural que integra cinema, televisão, música, vídeo, quadrinhos e internet (envolvendo revistas, fãs-clubes, livrarias especializadas, sites, blogs e comunidades virtuais), 
que dialoga com uma parcela específica do público que, como ele sugere, podemos qualificar de espectadores multimídia, parcela esta que estabelece formas diferenciadas e novos espaços para se relacionar com a produção cultural _ incluindo-se aí o "espaço virtual".

Como visto anteriormente, a intertextualidade é uma das marcas da estética pós-moderna, presente na produção cultural de vários artistas contemporâneos. Espectadores, leitores e ouvintes necessitam de amplas enciclopédias para compreender e relacionar a infinidade de citações presentes nas obras culturais contemporâneas, que vão do pop ao erudito. Se, no passado, coube à crítica fazer a mediação dessas informações para o público melhor compreender as obras, agora, muitas vezes, é uma parcela do próprio público que se propõe a assumir essa tarefa.

A essa altura da discussão pode ser esclarecedor considerar a distinção que em inglês é expressa pelos termos critic e reviewer. No caso do critic, o diálogo privilegiado é com os realizadores, com as pessoas que de um modo geral estão ligadas à produção cinematográfica, buscando emitir assim opiniões e conselhos que contribuam para estimular a produção e evitar possíveis equívocos. Já o reviewer, especialmente para os americanos, é a pessoa que escreve textos de natureza crítica com o propósito de orientar seus leitores, relatando suas próprias reações e compartilhando critérios de julgamento pessoal em relação à obra; cumpre, portanto, a função de guia, de comentador. É aqui que entram as novas possibilidades descortinadas pelas TICs. Nossa hipótese é de que as TICs - especialmente a Internet - multiplicaram os canais de expressão dos reviwers, ampliando o espaço de produção e circulação de informações culturais e reconfigurando os circuitos de crítica e mediação.

Diariamente surgem cada vez mais sites e blogs dedicados ao cinema, de crítica e/ou informação, produzidos pelos próprios espectadores (ou mesmo pelos realizadores; é o caso de alguns diretores de cinema, como Peter Greenaway e Quentin Tarantino, que mantém na rede seus próprios sites). O arco de opções vai de sites com um caráter mais genérico até aqueles mais especializados em determinados recortes: temas, períodos, gêneros narrativos, origem geográfica, diretores e/ou atores específicos, etc. São fontes importantes de informações para uma melhor compreensão das obras e dos universos culturais nelas referenciados. Ainda no universo audiovisual, outro segmento que recebe o mesmo tipo de atenção dos espectadores e fãs é o das séries televisivas. Comunidades de fãs de seriados, como Star Trek (os trekkies, como se autodenominam), são responsáveis por diversos sites e blogs, além de serem também produtores de guias, dicionários e glossários de termos relacionados a esse universo cultural.

No caso dos quadrinhos, podemos mencionar a "invasão inglesa" que ocorreu a partir dos anos 80 e modificou profundamente o estilo das histórias produzidas por editoras como a Marvel e a DC Comics norteamericanas. Autores como Neal Gaiman (Sandman, Livros da Magia), Alan Moore (Watchmen, HellBlazer, Promethea), Grant Morrison (Homem- 
Animal, Patrulha do Destino, Invisíveis) e Warren Elllis (Transmetropolitan, Planetary) criaram obras constituídas a partir de um universo de referências e citações internas ao próprio gênero e para além dele, cobrindo a literatura, o cinema, a música a política e a ciência. As próprias editoras passaram a incorporar a esses trabalhos glossários de termos, guias e textos com comentários para auxiliar o público em sua leitura. Como se isso não bastasse, também as comunidades de fãs/leitores passaram a produzir seus próprios fanzines, sites e blogs para disseminar informações, comentários e críticas acerca das obras.

Atividades mais antigas e tradicionais, como a leitura e a audição musical, também se modificaram. O ciberespaço tem sido apontado muitas vezes como vilão em relação à leitura, com um prognóstico bastante disseminado, que já se tornou senso comum, relativo ao "fim dos livros". Nada mais equivocado. Algumas indicações mostram que, ao contrário, o comércio livreiro na internet tem favorecido a ampliação da venda de livros ${ }^{4}$. Além disso, a internet tem propiciado a revivência (ou pelo menos a renovação) dos tradicionais "Clubes de Leitura", travestidos agora em comunidades de leitores ou plataformas sociais de troca de informação literária como a Anobii e a Skoob.

Em relação à música, a hibridização de gêneros e influências é uma característica marcante da produção contemporânea. As facilidades tecnológicas permitiram que a produção se tornasse mais fácil para os artistas. O grande nó continuaria sendo relativo à distribuição das obras, na medida em que os circuitos tradicionais de difusão ainda estariam nas mãos das grandes produtoras. A internet trouxe modificações importantes para esse quadro. Plataformas de redes sociais como o MySpace e o FaceBook tornaram-se canais de divulgação de novos artistas e suas produções (e, em alguma medida, laboratórios de experimentação de baixo custo para as grandes produtoras). Por outro lado, plataformas sociais de música como a Last $\mathrm{FM}$ ou de vídeo como o YouTube transformaram a maneira pela qual ouvintes e fãs podem se informar sobre música, com potenciais impactos nos processos de construção de identidades dos gêneros musicais.

Em muitos campos acadêmicos vai tornando-se corrente, aos poucos, a discussão de como os ambientes sistêmicos de recuperação da informação se modificaram a partir das novas condições tecnológicas virtuais, que reconfiguraram, inclusive, as formas pelas quais compreendemos o fenômeno da informação. Autores como Manuel Castells (1999) e Pierre Lévy (1999) referem-se à disseminação de um volume cada vez maior de informações pelas TICs e às formas de

4A internet aumentou a venda de livros no mundo ao invés de desestimula-lá, segundo análises de mercado. A editora Penguin anunciou que a explosão no varejo online e nas vendas de livros usados não causou os prejuízos que ela havia previsto e que, de muitas maneiras, a internet acabou beneficiando as livrarias, funcionando como ferramenta de marketing, experimentação e aproximação com a próxima geração de leitores. A editora Bloomsbury afirmou, por sua vez, que a mídia eletrônica é uma parte fundamental de seus negócios futuros, tanto que ela já fechou contratos de direitos com grupos como a Microsoft. (Internet fomenta venda de livros, diz análise. Info Exame www.infoexame.com.br Acesso em 12.03.2009) 
construção coletiva do conhecimento e de organização da sociedade em redes. O relacionamento dos usuários com a informação muda de foco:

A miscigenação entre conteúdos institucionalizados e públicos, somados às vozes dos especialistas e dos atores da vida cotidiana, desmembrou a solidez das garantias antes seguidas para representação e organização do conhecimento. [...] As práticas de colaboração, cooperação e associação entre interlocutores da rede tem sido um critério condicionante de validação de muitas das ações de busca da informação na Internet. (GRACIOSO, 2008, p. 159-162)

O que se percebe é que, cada vez mais, a possibilidade de fruição e de crítica das obras culturais depende do acesso a uma série de informações relacionadas a elas. O que presenciamos atualmente retoma, de certo modo, a concepção clássica da crítica como um julgamento de valor esclarecido e informado. O que ocorre, diferentemente de épocas anteriores, é que as TICs configuram agora a possibilidade de criação de espaços menos hierárquicos de circulação dessas informações, podendo fazer de cada consumidor cultural um potencial crítico ou mediador da informação. Nesse sentido, o surgimento das mídias sociais pode ser visto como um marco na abertura de novas possibilidades para a produção, circulação e fruição cultural.

As mídias sociais (alguns as denominam plataformas sociais) possuem algumas características que as diferenciam fundamentalmente das mídias tradicionais, como jornais, televisão, livros ou rádio. Basicamente, as mídias sociais dependem da interação entre pessoas, porque é a partir da discussão e da integração entre elas que o seu conteúdo será construído e compartilhado, usando a tecnologia informacional como recurso. Podem ser encaradas, portanto, como ferramentas online projetadas para permitir a interação social a partir do compartilhamento e da criação colaborativa de informação nos mais diversos formatos. Compreendem assim atividades diversificadas que integram tecnologia, interação social e a construção/circulação de textos, fotos, vídeos e áudios. Tanto a interação como a forma pela qual a informação será apresentada vai depender das perspectivas e concepções de mundo da pessoa ou grupo que compartilhou esse conteúdo. As mídias sociais podem assumir formatos variados e mistos, como blogs, compartilhamento de fotos, videologs, scrapbooks, e-mail, mensagens instantâneas, compartilhamento de músicas, entre outros. O público pode participar de uma mídia social comentando ou até editando histórias, vídeos e músicas. O conteúdo de uma mídia social, em texto, gráficos, fotos, áudio ou vídeos podem ser misturados. Outros usuários podem criar conexões e serem avisados de atualizações através de ferramentas do sistema. Uma última característica das mídias sociais é seu potencial de acúmulo de informações: não existe um limite, um número prédeterminado de páginas ou horas de utilização.

Dois exemplos podem ilustrar melhor o que está em questão. No caso dos livros existe uma rede social de leitores presentes na Internet, 
que é a aNobii (http://www.anobii.com). Trata-se de um clube de leitores no ciberespaço onde é possível compartilhar referências e opiniões acerca do que cada leitor já leu, do que está lendo ou mesmo do que pretende ler. Cada leitor cadastrado ganha uma "estante virtual" que pode ser preenchida a partir dos dados gerados pelo sistema com o número ISBN dos livros. Essa comunidade oferece aos leitores diversas opções: definir como o livro foi adquirido, como rastrear empréstimos, qual o status da leitura, a opção de deixar o exemplar disponível para troca, dar uma nota para a obra, criar etiquetas (tags). Estas últimas permitem classificar os livros a partir de categorias já existentes e utilizadas por outros leitores ou a partir de categorias criadas especificamente por cada leitor para seu uso próprio. Também há a possibilidade de criar uma "lista de desejos", com os livros que se gostaria de ter e/ou ler. Assim que a estante do usuário se encontra pronta e salva (ou pelo menos parte dela), torna-se disponível para a visita por parte de outras pessoas da comunidade, e o próprio site encarrega-se de encontrar automaticamente pessoas que compartilhem o mesmo gosto literário do leitor. A partir daí é fácil usar o sistema, que também pode funcionar como uma forma de catalogação da biblioteca pessoal de cada leitor. Em alguma medida, constitui-se um espaço "público" de exercício da crítica e do debate, com a possibilidade aberta a cada leitor de manifestar sua opinião acerca tanto dos livros lidos como dos comentários de outros leitores. Presencia-se, aqui, uma mutação do perfil do leitor, que pode acumular agora os papéis de autor, crítico e bibliotecário de referência (ALMEIDA, 2009).

Já a Last.fm é uma plataforma social de compartilhamento de música. Na década de 90 Felix Miller e Martin Stiksel administravam uma gravadora on-line que divulgava músicas independentes quando conheceram o universitário Richard Jones, que começou a rastrear o que ele e seus amigos ouviam em seus computadores por meio de um projeto denominado Audioscrobbler. A Last.fm reuniu essas duas ações em uma única plataforma e tornou-se um serviço global de música, disponível em 12 idiomas, sendo adquirida pela CBS em 2007. Atualmente, o projeto permite que as pessoas escolham sozinhas as suas músicas. Quando um ouvinte recomenda uma música para um amigo, adiciona uma etiqueta, escreve sobre essa música ou simplesmente a ouve, ela ganha mais importância no site. A partir desse momento, ela poderá ser recomendada a diferentes pessoas, sendo incluída nas tabelas musicais da Last.fm. A plataforma torna disponíveis páginas wiki com informações que podem ser editadas por qualquer pessoa. A finalidade é fornecer uma descrição breve, concisa e imparcial do artista ou selo, por exemplo, informações básicas sobre pessoas e/ou grupos, o tipo de música que eles tocam, as categorias pelas quais são mais conhecidos, etc. No plano mais opinativo, são oferecidos outros locais para os usuários expressarem suas opiniões: páginas de resenhas, caixas de mensagens e fóruns de discussão.

Nos dois casos estamos diante de práticas de construção coletiva de hipertexto denominadas de etiquetagem social (social tagging) ou folksonomias. Muito embora não haja necessariamente contato dialógico entre os participantes, a folksonomia baseia-se num processo coletivo e 
interativo por meio das etiquetas atribuídas (tags). Para o autor do termo folksonomia, T. Wander Wal (2007), ela é o resultado de um processo livre e coletivo de atribuição de etiquetas classificatórias a páginas e objetos com o intuito de recuperar posteriormente essa informação. Diferentemente do início da Web, onde apenas programadores e conhecedores da linguagem de programação estavam habilitados a editar hipertextos, agora qualquer usuário da informação pode participar desse processo. No caso específico da Last.fm foi observado que

As tags não precisam necessariamente estar vinculadas com o gênero/estilo musical em si e podem agregar valores subjetivos como "breakfast radio" (rádio do café da manhã), "músicas que eu amo", "música mais gay de todos os tempos" (essa foi uma das tags encontradas para as canções da cantora Madonna), etc. No caso de cenas e culturas musicais específicas há também as junções de um ou mais gêneros, como exemplo a tag hellektro, que é uma derivação de dois subgêneros da música eletrônica. (AMARAL e AQUINO, 2008, p. 3)

As etiquetas funcionam como marcadores didáticos e/ou codificadores sintéticos de um gênero ou subgênero específico, remetendo, no caso da música, a determinadas sonoridades caracteristicamente definidas, e, no caso da literatura, a traços estilísticos, temáticas e/ou posicionamentos ideológicos e comportamentais. Em contextos específicos, estas formas de organizar a informação podem apontar para traços culturais que incluem vocabulários especializados e gírias, comportamentos, rituais, trajes, etc. que indicam sua força potencial na construção/desconstrução de identidades e subjetividades tanto no plano virtual como no plano presencial das vidas das pessoas.

\section{Considerações finais}

A intertextualidade característica da produção cultural pós-moderna, que configura o horizonte de expectativas dos leitores, ouvintes e telespectadores tornou-se, graças às novas tecnologias, também acessível em parte aos consumidores culturais. As plataformas sociais como as que aqui foram mencionadas possibilitam, seguindo as sugestões de Umberto Eco, a ampliação das competências enciclopédicas e intertextuais dos consumidores culturais contemporâneos. Um dos aspectos mais interessantes desse processo consiste no fato de que ele está se desenvolvendo de forma coletiva e colaborativa, colocando em xeque alguns pressupostos relativos às clivagens socioculturais decorrentes das diferenciações relacionadas à posse de atributos educacionais, institucionais, econômicos e de outra natureza que permeariam o universo das práticas culturais.

Ao organizarem, classificarem e avaliarem os produtos culturais das formas descritas anteriormente, os usuários deslocam do lugar, em alguma medida, os especialistas - críticos, jornalistas, bibliotecários e 
afins - que construíam e legitimavam as antigas categorizações. Discussões envolvendo a autenticidade e pertinência de determinados subgêneros musicais, as qualidades literárias do último best-seller em voga ou mesmo os critérios da crítica para julgar os trabalhos dos artistas, são levadas a cabo em múltiplas plataformas e fóruns. Não se está apontando, com isso, a falência total e a substituição dos antigos modelos e espaços de legitimação cultural; na verdade, alguns desses modelos permanecem, adaptando-se aos novos recursos (vide Sanches, 2007). O que se aponta é a capacidade de determinados grupos em desdobraremse e negociarem suas identidades e valores em distintos locais e redes, descentralizando em alguma medida os processos de circulação e legitimação das informações e conhecimentos sobre a produção cultural. Se ainda é prematuro falar-se num processo de "democratização" do acesso à informação cultural e de novas práticas dos usuários, fica patente, por outro lado, que o processo tecnológico em curso descortina possibilidades inéditas e promissoras nesse sentido. Cabe aos pesquisadores afinarem seus olhares e instrumentos para compreender melhor esses fenômenos.

\section{Referências}

ADORNO, Theodor; HORKHEIMER, Max. Dialética do esclarecimento: fragmentos filosóficos. Rio de Janeiro: Jorge Zahar, 1986.

ALMEIDA, Marco Antonio de. A cada leitor seu texto: dos livros às redes. Encontros Bibli. Edição Especial - primeiro semestre 2009: Pesquisas em Ciência da Informação no Brasil e no Canadá, p. 154-173. Disponível em: http://www.periodicos.ufsc.br/index.php/eb/issue/current

ALTAMIRANO, Carlos \& SARLO, Beatriz. Literatura/Sociedad. Buenos Aires: Edicial, 1993.

AMARAL, A., AQUINO, M.C. Práticas de folksonomia e social tagging no Last.fm. Artigo apresentado no IHC'08. Simpósio Brasileiro sobre Fatores Humanos em Sistemas Computacionais, PUCRS, 2008. Disponível em http://papersadriamaral.wetpaint.com/?t=anon

BOURDIEU, Pierre. La distinction. Paris, Minuit, 1979.

As regras da arte: gênese e estrutura do campo literário. São Paulo: Companhia das Letras, 1996.

CANCLINI, Néstor Garcia. Consumidores e cidadãos: conflitos multiculturais da globalização. Rio de Janeiro: Ed. da UFRJ, 1995.

Culturas híbridas: estratégias para entrar e sair da modernidade. São Paulo: EDUSP, 1997.

Lectores, espectadores e internautas. Barcelona: Gedisa, 2007.

CASTELLS, Manuel. A era da informação economia, sociedade e cultura. Vol. I (A sociedade em rede). São Paulo, Rio de Janeiro: Paz e Terra, 1999. 
CATARINO, Maria Elisabete; BAPTISTA, Maria Alice. Folksonomia: um novo conceito para a organização dos recursos digitais na Web. In: DataGramaZero - Revista de Ciência da Informação v. 8 n. 3 jun/07. Disponível em http://dgz.org.br/jun07/Art 04.htm

ECO, Umberto. Apocalípticos e integrados. São Paulo: Perspectiva, 1979. . Lector in fabula. São Paulo: Perspectiva, 1986.

- O texto, o prazer, o consumo; Inovação no seriado. In:

Sobre os espelhos e outros ensaios. Rio de Janeiro: Nova Fronteira, 1989, pp. 100-109 e 120-139.

GRACIOSO, Luciana de Souza. Filosofia da linguagem e ciência da informação: jogos de linguagem e ação comunicativa no contexto das ações de informação em tecnologias virtuais. Tese de Doutorado. Rio de Janeiro: IBICT-UFF, 2008.

HABERMAS, Jürgen. Mudança estrutural na esfera pública. Rio de Janeiro: Tempo Brasileiro, 1984.

HUTCHEON, Linda. Pós-Modernismo: história, teoria, ficção. Rio de Janeiro: Imago, 1991.

INTERNET fomenta venda de livros, diz análise. Info Exame. Disponível em http://www.infoexame.com.br Acesso em 12.03.2009.

JAMESON, Fredric. Pós-Modernismo: a lógica cultural do capitalismo tardio. São Paulo: Ática, 1996.

LÉVY, Pierre. Cibercultura. São Paulo: Ed. 34, 1999.

MENDO, Anselmo Jiménez. História em quadrinhos: impresso vs. Web. São Paulo: Editora Unesp, 2008.

MAUSS, Marcel. Ensaio sobre o dom: formas e razões de troca nas sociedades arcaicas. In: Sociología e Antropología. São Paulo: EPU/EDUSP, 1974, vol. II.

RECUERO, Raquel da Cunha. Teoria das Redes e Redes Sociais na Internet: Considerações sobre o Orkut, os Weblogs e os Fotologs. Artigo no site do Grupo de Pesquisa Mídias Digitais. Disponível em http://www. midiasdigitais.org/?cat $=137$

SANCHES, Wilken David. O movimento de software livre e a produção colaborativa do conhecimento. Mestrado em Ciências Sociais. São Paulo: Pontifícia Universidade Católica (PUC-SP), 2007.

SPYER, Juliano. Conectado: o que a internet fez com você e o que você pode fazer com ela. Rio de Janeiro: Jorge Zahar, 2007.

TOLILA, Paul. Cultura e economia. São Paulo: Itaú Cultural: Iluminuras, 2007.

WAL, Thomas Vander. Folksonomy Coinage and Definition. Fevereiro/2007. Disponível em http://www.vanderwal.net/folksonomy.html 
WATT, Ian. A ascensão do romance: estudos sobre Defoe, Richardson e Fielding. São Paulo: Companhia das Letras, 1990.

WILLIAMS, Raymond. Cultura. Rio de Janeiro, Paz e Terra, 1992.

- Palavras-chave: um vocabulário de cultura e sociedade. São Paulo: Boitempo, 2007. 